\title{
Arranjos comunitários, sistemas produtivos e aportes de ciência e tecnologia no uso da terra e de recursos florestais na Amazônia Communities arrangements, productive systems, scientific and technological inputs for land use and forest resources in Amazon
}

\author{
Wanderley Messias da Costa ${ }^{1}$
}

Resumo: $\bigcirc$ foco principal deste trabalho é o exame de algumas das tendências atuais que estão promovendo mudanças significativas nos padrões de uso econômico dos produtos florestais amazônicos. Em termos gerais, essas novas tendências expressam, sob diversos modos, um amplo processo de modernização das atividades produtivas, no qual comunidades organizadas da região estão se estruturando segundo vetores desencadeados pelo impulso de cadeias produtivas complexas e suas respectivas redes. Por outro lado, elas também expressam a ampliação e a crescente sofisticação dos mercados de consumo para os produtos naturais em geral, os produtos florestais em particular e, especialmente, para aqueles da biodiversidade amazônica. Finalmente, esses sistemas produtivos emergentes passaram a contar com um aliado poderoso nos últimos anos, representado por sua crescente interação com as atividades de Ciência e Tecnologia (C\&T) e de Pesquisa e Desenvolvimento (P\&D), cujos resultados já podem ser observados em diversas experiências em curso, tais como ganhos de qualidade, de produtividade, de escala, de competitividade e, como consequência principal, a conquista de novos mercados de consumo.

Palavras-chave: Produtos florestais. Indústria madeireira. Sistemas emergentes. Novas tecnologias. Uso da terra. Amazônia.

Abstract: The main focus of this paper is the examination of some of the current trends in Brazilian Amazon that are promoting significant changes in the standards of economic use involving some rain forests products. These new trends are demonstrating, in resume, an extensive modernization of economic activities that affect specifically the structure and dynamics of organized communities in this region. On the other hand, these trends also affect the linkage of these communities with the respective networking in each case. In many cases, the type of region networking is leaded by industrial companies. The research also indicate that the main sources of this new process are the market increase for products extracts in Amazon biodiversity, and beside this, both scale and level of processing. Finally, it approaches another strategic source of modernization, represented by a closer and effective participation of regional scientific research institutions in these new or 'emerging systems'.

Keywords: Forest products. Timber industry. Emerging systems. New technologies. Land use. Amazon.

Universidade de São Paulo. Departamento de Geografia. São Paulo, São Paulo, Brasil (wander@usp.br).

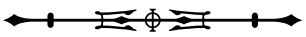




\section{INTRODUÇÃO'}

Como ponto de partida, assume-se aqui a ideia geral de que persistem e coexistem na Amazônia duas tendências dominantes quanto às formas de organização do trabalho e às estruturas de produção relacionadas diretamente a essa modalidade de uso dos recursos florestais.

Uma delas está relacionada às inúmeras e seculares modalidades de uso desses recursos pelas populações tradicionais amazônicas, organizadas sob a forma de trabalho familiar e/ou comunitário e com níveis variados de conexão com os mercados regional e nacional ${ }^{2}$. Esses sistemas típicos da vida regional amazônica são aqui denominados de extrativismo tradicional.

A outra, mais recente, expressa por diversos modos um amplo processo de modernização dessas atividades, pelo qual as comunidades tendem a se estruturar em novas modalidades sob o impulso de cadeias produtivas e respectivas redes lideradas pela bioindústria. Na nossa abordagem, essa nova conectividade entre organizações comunitárias e empresas bioindustriais é denominada de 'sistemas produtivos emergentes' (Costa, 2007).

Apesar dos diversos aspectos comuns a esses dois sistemas predominantes, tais como o extrativismo, o agroextrativismo, a pequena produção familiar e/ou a organização comunitária, observa-se atualmente uma tendência de acentuação das distinções entre eles, um processo que está relacionado ao crescimento atual da importância do segundo tipo de exploração florestal, o qual tem sido impulsionado, sobretudo, pela ação combinada de três vetores principais.

O primeiro é a ampliação e a crescente sofisticação dos mercados de consumo para os produtos naturais em geral, os produtos florestais em particular e, especialmente, para aqueles oriundos da chamada biodiversidade amazônica.

O segundo é a incorporação de novas tecnologias em toda a cadeia produtiva dessas atividades, processo que pode ser basicamente relacionado à maior conectividade entre as atividades de Ciência e Tecnologia (C\&T) e de Pesquisa e Desenvolvimento (P\&D) desta e de outras regiões com aqueles sistemas e, adicionalmente, às novas exigências dos mercados de consumo expressas em mecanismos diversos de autorregulação que têm sido adotados para a certificação de qualidade em geral e, especificamente, ambiental.

terceiro está associado às modalidades mais avançadas de produção e de integração e à nova logística introduzidas pelas grandes empresas agroindustriais - as empresas-líderes - que compõem atualmente os setores produtivos 'não-convencionais' ${ }^{3}$ e que têm impulsionado a rápida modernização do extrativismo (e do agro-extrativismo) florestal, da produção familiar e da organização comunitária (cooperativas de pequenos produtores), com destaque para os sistemas bioindustriais relacionados à fruticultura em geral, à produção do guaraná, do dendê (não-florestal e florestal) e, especialmente, às matérias-primas e aos insumos semiprocessados e processados para as indústrias de fitocosméticos e de fitofármacos ${ }^{4}$ da região e de fora dela.

\section{SISTEMAS EMERGENTES NO USO DE PRODUTOS FLORESTAIS NÃO-MADEIREIROS}

Levantamentos e estudos recentes, de modo geral, têm indicado o dinamismo desses sistemas, que, entre outras características, combinam processos de consolidação e de expansão na região e, ao mesmo tempo, demonstram

1 Este texto tem como base principal uma abrangente pesquisa sobre esses temas que desenvolvemos no âmbito do Projeto Nacional para o Desenvolvimento da Amazônia - "Desafios para o Projeto Amazônia", elaborada junto ao Centro de Gestão e Estudos Estratégicos (CGEE) em 2008, cuja íntegra (com as bases de dados, quadros, gráficos e mapas) foi publicada em 2009.

2 Ver as contribuições de Mary Helena Allegretti (2008).

3 Para fins de diferenciação dos sistemas agroindustriais, são aqui considerados como 'convencionais' principalmente os grandes empreendimentos relacionados à pecuária, à exploração madeireira, à mineração e ao cultivo de grãos em larga escala (especialmente a soja).

4 Há inúmeros documentos técnicos, produzidos principalmente no âmbito do Ministério do Meio Ambiente/Programa Brasileiro de Ecologia Molecular (MMA/PROBEM) e da Organização Social Bioamazônia, sobre as potencialidades e as experiências de utilização econômica da biodiversidade da Amazônia para esses segmentos industriais. Uma análise abrangente sobre esse e outros programas do gênero e as tendências recentes da bioindústria na Amazônia encontra-se no trabalho de Miguel (2007).

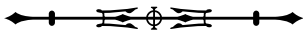


outras faces positivas (fatores, estímulos ou vetores) com potencial para promover mudanças diversas nos circuitos de produção e na qualidade de vida das populações, como é o caso do processo de revitalização de algumas áreas rurais tradicionais da região caracterizadas pela predominância da pequena produção familiar (como no nordeste do Pará), e de núcleos ribeirinhos como aqueles situados no baixo e no médio Amazonas/Solimões (Tabela 1).

Eles também podem ser considerados como uma alternativa que tem se mostrado comprovadamente eficiente para o aproveitamento de áreas desmatadas, degradadas ou abandonadas, com destaque para aquelas associadas à exploração predatória de recursos madeireiros ou ao fracasso de grandes empreendimentos agropecuários, como são os inúmeros casos daqueles instalados a partir dos anos setenta sob o impulso das políticas públicas de ocupação acelerada da região e dos incentivos fiscais regionais em especial.

Além disso, as suas diversas modalidades de interações com os aparatos de C\&T e de P\&D têm promovido a mobilização de grupos, redes e instituições de pesquisa (principalmente da região) e as agências nacionais e estaduais de fomento, concentrando o foco, sobretudo, na biotecnologia em geral aplicada à agricultura e ao uso sustentável da biodiversidade (casos dos projetos de genoma de espécies ou do desenvolvimento de variedades mais resistentes a pragas etc.), cujos resultados contribuem fortemente para os ganhos de produtividade e para a elevação dos padrões de qualidade de processos e produtos em todos os steps das cadeias produtivas desses sistemas.

Os últimos anos têm registrado um vigoroso processo de crescimento e diversificação de grupos e redes de pesquisas em operação na região, envolvendo instituições diversas, com destaque para aquelas lideradas pela Empresa Brasileira de Pesquisa Agropecuária (EMBRAPA), o Instituto Nacional de Pesquisas da Amazônia (INPA), a Universidade Federal do Pará (UFPA) e a Universidade Federal do Amazonas (UFAM). O projeto de genoma mencionado, por exemplo, foi desenvolvido por uma rede de pesquisadores criada pelo Conselho Nacional de Desenvolvimento Científico e Tecnológico (CNPq) e liderada por um grupo da UFAM e do INPA, e resultou no sequenciamento genético do guaraná. Projeto semelhante envolvendo uma parceria da EMBRAPA com - Centre de Coopération Internationale en Recherche Agronomique pour le Développement (CIRAD, França)

Tabela 1. Produtos florestais não-madeireiros e cultivo do dendê na Amazônia - 2007 (toneladas).

\begin{tabular}{l|c|c|c|c|c|c|c|c}
\hline \multicolumn{1}{c|}{ Estados } & Dendê & Guaraná & Açaí & Castanha & Urucum & Fibras & $\begin{array}{c}\text { Plantas medicinais } \\
\text { e aromáticas }\end{array}$ & $\begin{array}{c}\text { Óleo de } \\
\text { copaíba }\end{array}$ \\
\hline Acre & - & 61 & 961 & 10.217 & 72 & 52 & - & - \\
\hline Amapá & - & - & 1.160 & 917 & - & - & - & - \\
\hline Amazonas & 183 & 1.156 & 1.172 & 9.165 & 82 & 9.131 & - & 443 \\
\hline Maranhão & - & - & 9.441 & - & 143 & 142 & 957 & - \\
\hline Mato Grosso & - & 290 & - & 473 & 94 & - & - & 27 \\
\hline Pará & 1.031 .004 & 31 & 88.547 & 5.291 & 1.473 & 267 & 12 & 25 \\
\hline Rondônia & - & 49 & 56 & 2.652 & 1.855 & - & - & 7 \\
\hline Roraima & - & - & - & 91 & - & - & - & - \\
\hline Tocantins & - & - & 3 & - & - & 1 & - & - \\
\hline Região & 1.031 .187 & 1.587 & 101.340 & 28.806 & 3.719 & 9.593 & 969 & 502 \\
\hline Brasil (total) & 1.207 .276 & 2.989 & 101.340 & 28.806 & 11.097 & 83.763 & 1.705 & 502 \\
\hline Era
\end{tabular}

Fonte: Pesquisa Agrícola Municipal, Instituto Brasileiro de Geografia e Estatística (IBGE), 2008.

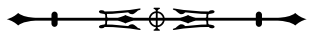


dedica-se atualmente à realização do sequenciamento genético do dendê.

Há inúmeras outras pesquisas concluídas e em andamento, como aquelas desenvolvidas há mais de uma década pelo grupo de pesquisadores do Instituto de Química da UFPA e do Museu Paraense Emílio Goeldi (MPEG), e que resultou no que poderíamos denominar de um 'inventário químico e bioquímico' de espécies da biodiversidade amazônica de interesse econômico, com destaque para as plantas aromáticas que são fontes conhecidas de óleos essenciais utilizados nos segmentos de perfumaria, cosméticos e medicamentos em geral (Maia et al., 2001). Merecem também menção as contribuições do grupo de pesquisadores do INPA que se dedica há anos a diversos estudos visando à identificação de oportunidades de exploração econômica de plantas para uso em fitocosméticos e fitomedicamentos, bem como de fruteiras nativas para produtos comercializados in natura ou processados industrialmente ${ }^{5}$.

Cabe destacar também impactos de outra natureza, tais como a 'internalização' e a consolidação na economia regional em geral (e não apenas nesses sistemas) dos diversos mecanismos atuais de certificação de qualidade para processos e produtos, uma tendência que induz e introduz exigências de competitividade e novos paradigmas no processo produtivo e que representa, por isso, um poderoso vetor de modernização, posto que ele expressa nas escalas locais e regionais os padrões tecnológicos vigentes nos mercados nacionais e internacionais.

Um dos exemplos mais expressivos dessas mudanças em curso é aquele representado pela consolidação e expansão de pequenos empreendimentos industriais nesses segmentos, com destaque para os que têm se dedicado à produção de matérias-primas, insumos e produtos acabados na área dos fitocosméticos e (com menor intensidade) na dos fitoterápicos tradicionais. A aprovação do Processo Produtivo Básico (PPB) (no final de 2007) para o promissor segmento dos cosméticos no âmbito do pólo industrial de Manaus é medida no campo regulatório que possui potencial capaz de dinamizar o processo de expansão do incipiente pólo bioindustrial específico para essa atividade.

Já é observável também a introdução de novas formas de associativismo comunitário, com o predomínio das cooperativas rurais, das microempresas familiares agroindustriais ou das associações de pequenos produtores (como no extrativismo de novo tipo) sob estruturas empresariais diversas. Esse processo inclui algumas experiências recentes envolvendo comunidades de assentamentos rurais, conectando-as sob várias formas a essas estruturas produtivas. Em outros termos, trata-se de uma nova dinâmica que tem propiciado a constituição de redes de produção e de comercialização, envolvendo os arranjos mais conectados do interior e os empreendimentos industriais de diversos portes dos centros urbanos.

A expansão e a distribuição desses novos arranjos comunitários do interior e as suas crescentes relações com pequenas, médias e grandes empresas de nascentes pólos de bioindústria (principalmente os de Manaus e Belém), e que têm se dedicado principalmente às cadeias produtivas dos fitocosméticos, estão ilustradas na Figura 1.

Registre-se, ainda, que as novas tendências no campo das modalidades mais avançadas de associativismo, ou de organização comunitária, cujos sistemas de produção mantêm atualmente intensas relações com os mercados nacionais e internacionais, representam, de certo modo, a consolidação e a reprodução de experiências mais antigas e bem sucedidas na região, como são os conhecidos exemplos da Cooperativa Agrícola Mista de Tomé-Açú (CAMTA) (uma colônia japonesa com mais de 70 anos) e da Cooperativa Agroindustrial de Trabalhadores e Produtores Rurais de Igarapé-Miri (COOPFRUT), ambas no Pará, da Cooperativa Mista dos Guaranacultores de Maués (COPAGUAM) e da Cooperativa Agrícola de Maués (CAMAU), no Amazonas.

\footnotetext{
5 Esse esforço é ilustrado pelas contribuições reunidas nos trabalhos de Revilla (2000) e de Clay et al. (1999).
}

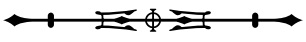




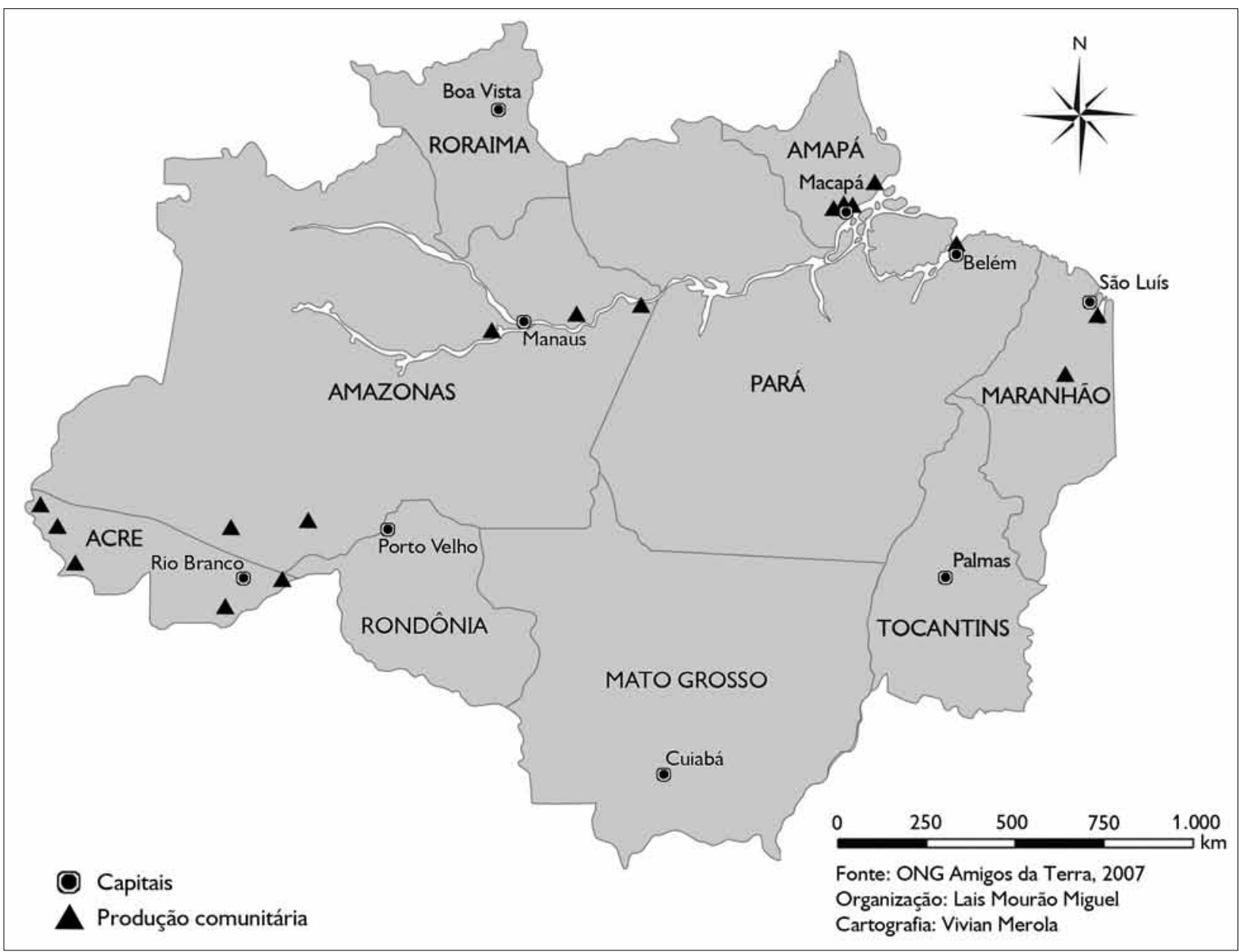

Figura 1. Exemplos de produção comunitária na Amazônia Legal.

Finalmente, devem ser destacados na atual conjuntura dois desses sistemas bem sucedidos, aqueles estruturados para a produção do dendê e do guaraná - produtos em franca ascensão nos mercados nacionais e internacionais - e que impulsionam na região a organização de circuitos agroindustriais e arranjos específicos que articulam diversas experiências de cooperativismo e as respectivas empresas-líderes desses segmentos. Por isso, eles têm sido considerados como os mais representativos dessa modalidade avançada de aproveitamento dos recursos florestais não-madeireiros e do bem-sucedido cultivo do dendê (uma planta exótica plenamente adaptada à região) para os novos segmentos associados aos 'bioprodutos'.

\section{A PRODUÇÃO DO ÓLEO DE DENDÊ}

O cultivo do dendê e a extração de seu óleo para aplicações diversas constituem atualmente uma das mais importantes atividades agroindustriais envolvidas com a produção de óleos vegetais em todo o mundo. As vantagens do dendê sobre outras culturas desse gênero têm se demonstrado particularmente notáveis, sobretudo em regiões de clima tropical úmido, a exemplo do Sudeste Asiático e da Amazônia. Diversos indicadores de desempenho atestam a sua superioridade sobre seus congêneres, especialmente a soja, o girassol e a colza. Entre outros, destacam-se o seu elevado teor de óleo (por volta de 20\%), o manejo relativamente simples, o curto período entre o plantio e

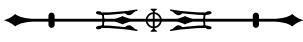


o início da produção (aproximadamente três anos), a alta produtividade e a perenidade das plantas (até 30 anos).

Além disso, devem ser destacadas as suas inegáveis qualidades como cultura tropical destinada à ocupação ou à reocupação de áreas desmatadas e/ou degradadas, bem como de áreas florestais alteradas sob diferentes graus. Isto se deve tanto à sua capacidade de fixação de nutrientes e de absorção de $\mathrm{CO}_{2}$, por exemplo, quanto a uma peculiaridade do seu cultivo, que é a utilização de leguminosas como forrageiras destinadas a proteger o solo contra as plantas invasoras e a erosão. Em suma, além do sucesso econômico, o dendê é um excelente cultivo para promover a recolonização biológica de áreas desmatadas ou enquanto um adequado plantio para integrar sistemas agroflorestais em geral.

Outras vantagens do palm oil estão associadas à sua multiplicidade de usos em função do largo espectro de derivados e subprodutos por ele gerados, tanto alimentícios, como não alimentícios. No caso dos primeiros, os principais usos abrangem o óleo para fritura, biscoitos, sorvetes, salgadinhos extrusados, alimentos para bebês, cereais matinais, margarinas, produtos lácteos, pães e preparados para bolos, gorduras vegetais, entre outros. No campo da oleoquímica, a sua mais conhecida aplicação é como óleo combustível, visto que ele substitui com vantagens o óleo diesel. Além disso, diversas de suas frações têm sido crescentemente utilizadas como matérias-primas para a produção de sabões e sabonetes, por exemplo, e como bases e insumos para artigos de cosméticos, de higiene e de limpeza, entre outros.

Em 2007, a produção mundial de palm oil superou pela primeira vez a do óleo de soja e a expansão recente do seu cultivo para novas áreas, como Papua Nova Guiné e a Amazônia brasileira, indica que deverá ampliar essa posição de liderança nesse importante mercado. Atualmente, os dois maiores produtores mundiais são a Indonésia e a Malásia, com aproximadamente 16 milhões de toneladas/ano para cada um desses países, os quais também lideram o ranking dos maiores exportadores desse produto (cerca de 26 milhões de toneladas/ano). Em 2006, a Malásia faturou US\$ 32 bilhões com a exportação de palm oil e em 2008 implantou - a exemplo do Brasil - o seu programa de biodiesel, tendo por base esse óleo vegetal, iniciando-o com a adição de 5\% em todo o óleo diesel consumido no país.

As perspectivas de expansão desse cultivo na região da Ásia-Pacífico são enormes para os próximos anos e já atingem atualmente novos países produtores, como Papua Nova Guiné. Há um evidente esforço nesses países em investimentos de P\&D visando elevar a produtividade e consolidar os diversos processos de certificação de toda a cadeia produtiva, além de programas governamentais destinados a consolidar os sistemas integrados que articulam as cooperativas de pequenos produtores familiares e as grandes empresas do segmento ${ }^{6}$.

No caso brasileiro, apesar da demonstrada vocação da Amazônia para a produção de dendê em larga escala, essa atividade ainda é incipiente. Como consequência, tem crescido nos últimos anos a dependência do país pelo fornecimento externo do produto, principalmente do óleo refinado, mais utilizado pelas indústrias (importação de 18,3 mil toneladas de óleo bruto e 80,2 mil toneladas de óleo refinado em 2008).

Os maiores cultivos do país estão localizados no Pará (Figura 2) e a empresa mais importante desse segmento é o Grupo Agropalma, responsável por cerca de $70 \%$ da produção nacional, desenvolvendo essa atividade em uma área de 107 mil ha, principalmente nos municípios de Tailândia, Acará e Moju, na qual envolve cooperativas de pequenos produtores, como mencionado acima. Nos últimos anos, esses cultivos estenderam-se para novos

\footnotetext{
6 Entre essas diversas iniciativas, merecem destaque as que têm sido desenvolvidas no âmbito da Roundtable on Sustainable Palm Oil (RSPO), um consórcio que integra empresas agroindustriais e industriais, produtores rurais, organizações ambientalistas e sociais (como o World Wildlife Fund - WWF) e representantes de governos de todos os níveis, que têm atuado intensamente para disseminar as novas práticas relacionadas às atuais exigências de qualidade para processos e produtos (RSPO, 2007).
}

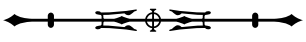




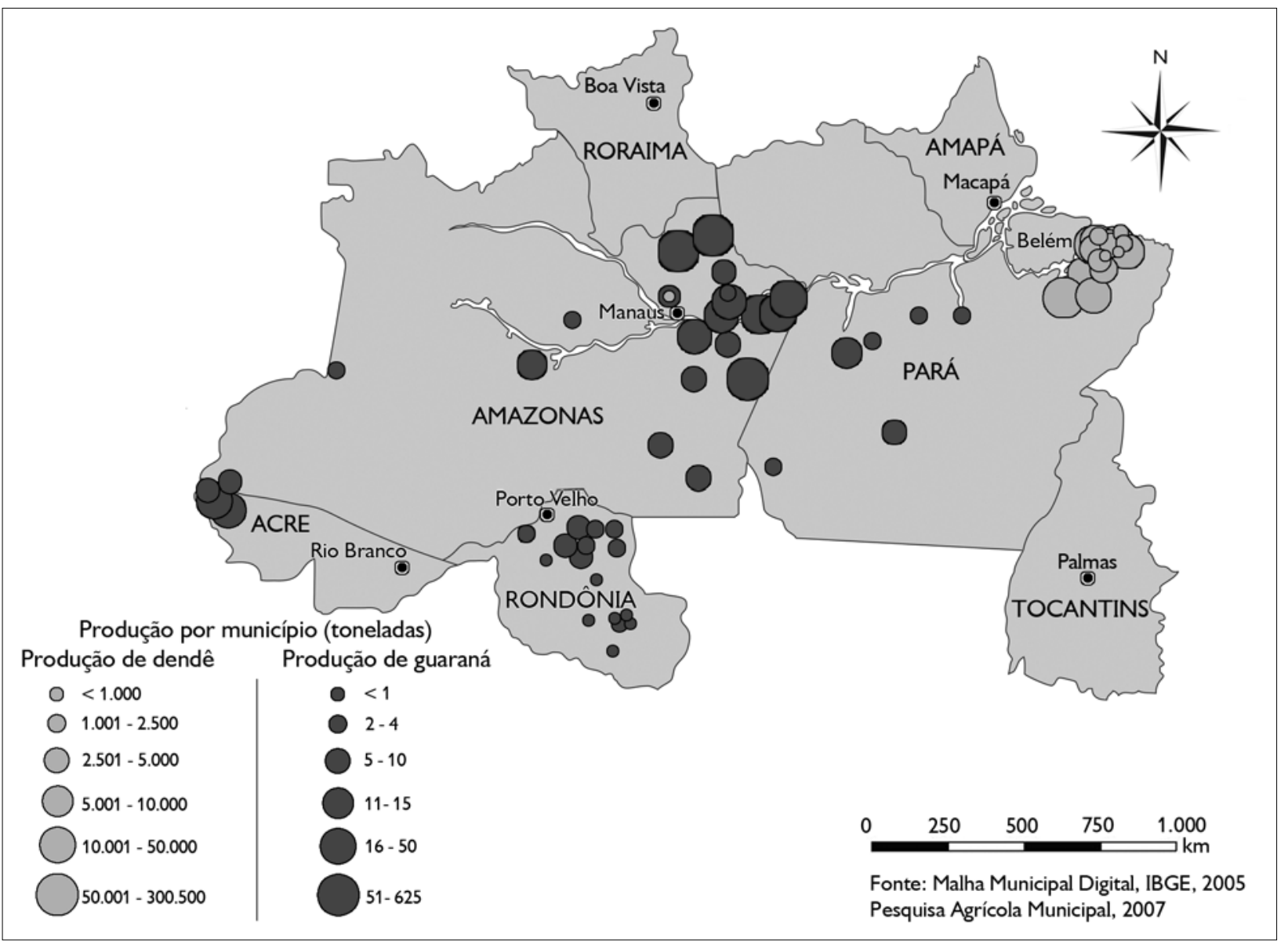

Figura 2. Produção de dendê e guaraná em 2007 (toneladas).

municípios, como Benevides, Santa Izabel do Pará, Santo Antonio do Tauá, Castanhal, Igarapé-Açú, no nordeste paraense e, com isso, a produção total do estado em 2006 foi de, aproximadamente, 750 mil toneladas de óleo bruto (Monteiro et al., 2006).

Em 2008, entrou em funcionamento o mercado nacional de biodiesel, tendo como base a adição de $2 \%$ de óleo vegetal ao diesel. Apesar do predomínio do óleo de soja, ampliaram-se as perspectivas favoráveis para a expansão do palm oil na região. Tomando como base as novas tendências do mercado brasileiro, levantamentos e estudos realizados pela EMBRAPA estimam que 0 estado do Pará dispõe de cerca de 5 milhões de hectares aptos para o cultivo do dendê. Além disso, a EMBRAPA implantou recentemente um pólo experimental de cultivo e extração desse óleo no município de Rio Preto da Eva, no Amazonas, havendo também registros de novos investimentos de empresas privadas em curso nesses dois estados, além de Rondônia e Roraima.

\section{A PRODUÇÃO DE EXTRATO DE GUARANÁ}

O cultivo do guaraná se destina, sobretudo, para a produção de extrato vegetal e concentrados, que são empregados na formulação de refrigerantes. Atualmente, o maior produtor nacional é a Bahia (hoje em fase de declínio), secundado pelo Amazonas (em fase de rápida expansão) e pelo Mato Grosso. No Amazonas, a produção está concentrada nos municípios de Maués (a maior parte) e de Presidente

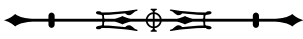


Figueiredo, e se desenvolve principalmente em sistemas integrados comandados pelas empresas-líderes desse setor, como a AmBev e a Coca-Cola. A atividade envolve a participação direta de pelo menos duas grandes cooperativas e de 12 pólos agrícolas de pequenos produtores em um grupo de municípios daquele estado, tendo Maués à frente (Barreirinha, Urucará, Boa Vista do Ramos e Parintins).

O sistema funciona em torno de um pólo bioindustrial produtor de extratos e xaropes localizado em Manaus, cuja produção se destina em sua quase totalidade para o mercado externo e se constitui hoje num dos principais itens da pauta de exportações do Pólo Industrial de Manaus $(\mathrm{PIM})^{7}$. Com a crise dos cultivos na Bahia, aliada aos ganhos de produtividade na Amazônia, é enorme a potencialidade de expansão desses sistemas integrados na região, especialmente no Amazonas, onde se tem incorporado novas áreas de produção, a exemplo de Presidente Figueiredo, que possui, em relação a Maués, vantagens como o uso de novas tecnologias de produção e a maior facilidade de acesso a Manaus. Finalmente, tem se fortalecido nos últimos anos a tendência de introduzir o processo de certificação da atividade em toda a cadeia produtiva, incluindo o crescimento da demanda - principalmente do mercado internacional - pelo chamado guaraná orgânico.

\section{PERSPECTIVAS DA BIOPROSPECÇÃO NA AMAZÔNIA}

Os levantamentos e estudos atuais indicam - de modo geral - que, apesar da virtuosa combinação de processos de modernização e acelerada expansão, os sistemas emergentes ainda não superaram as suas limitações de origem.

No que se refere à utilização econômica dos produtos 'típicos' (nativos ou adaptados) amazônicos e os seus respectivos segmentos agroindustriais e industriais, os sistemas ainda estão restritos à exploração de espécies e famílias de espécies tradicionais, tanto na fruticultura, quanto nas matérias-primas e insumos em geral para os fitocosméticos, por exemplo.

Desse modo, os sistemas mantêm basicamente um padrão espacial tendente à concentração, que decorre, sobretudo, da sua alta dependência da disponibilidade de infraestrutura convencional (estradas, energia etc.) e nova (infovias, por exemplo), além da densidade da rede de cidades e da qualidade dos equipamentos e dos serviços dos centros urbanos, favorecendo, desse modo, as capitais dos estados e, especialmente, Belém e Manaus, com as suas respectivas redes ${ }^{8}$.

Como esses sistemas têm sido liderados exclusivamente por empresas privadas de grande porte (nacionais e internacionais), tendem a refletir as limitações impostas pela natureza e pelos objetivos desse tipo de investimento, por exemplo, o fato de que as empresas-líderes têm demonstrado um escasso (ou nenhum) interesse em estabelecer conexões de média e alta intensidade entre os sistemas e os pequenos empreendimentos das comunidades isoladas do interior profundo, um quadro que tende a mantê-las à margem da core area dessa modernização, e que tem contribuído para a reprodução de modalidades arcaicas de coleta e/ ou produção e comercialização.

As mais conhecidas entre as grandes empresas são a Agropalma (produção de dendê no Pará), a AmBev, a CocaCola e a Pepsi-Cola (guaraná e seus extratos no Amazonas), a Crodamazon (óleos essenciais no Amazonas), a Brasmazon e a Beraca (fitocosméticos no Pará), a Natura (insumos e produtos acabados de fitocosméticos no Pará) e a Amazon Ervas (produtos acabados de fitocosméticos e fitoterápicos no Amazonas). Há, ainda, um diversificado grupo de empresas nacionais que estão sediadas fora da região, mas que processam e/ou fabricam produtos acabados com base

\footnotetext{
Em 2007, foram exportados cerca de US\$131 milhões em extratos e concentrados desse produto, equivalentes a $12 \%$ do total das exportações do PIM.

8 Há diversos estudos recentes de Bertha Becker sobre essa e outras questões da Amazônia, podendo-se destacar: Becker (2004, 2007a, 2007b).
}

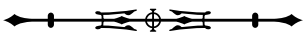


em matérias-primas e insumos amazônicos, destinando-os principalmente para exportação.

Por isso, a ação do Estado nesses circuitos é crucial em vários aspectos, mas especialmente nesse caso, visando disseminar e aprofundar os programas de apoio ao manejo florestal comunitário, a exemplo das bem sucedidas iniciativas de governos estaduais, como os do Acre, do Amazonas e do Amapá, principalmente, e aquelas do Governo Federal, como o Projeto de Desenvolvimento Sustentável (PDS) e o Projeto de Assentamento Florestal (PAF), conforme abordado anteriormente?

É preciso reconhecer que, apesar do vigor atual das atividades de Ciência, Tecnologia e Inovação (C\&T\&I) na região e dos seus impactos positivos na dinâmica daqueles sistemas, os programas e projetos com maior efetividade ainda estão, de modo geral, concentrados nos produtos e respectivos segmentos mais conhecidos e de maior sucesso comercial, como são os casos do guaraná, do dendê e da fruticultura associada ou não aos sistemas agroflorestais (como açaí, cupuaçu, pupunha etc.), uma tendência que é decorrente de alguns fatores conhecidos, como a insuficiência dos investimentos do governo federal nessa área para a região (vis-à-vis às demais do país), que se reflete nas limitações da capacidade instalada (infraestrutura laboratorial, entre outras) e na disponibilidade e formação de recursos humanos qualificados (doutores e pósdoutores) para as instituições de pesquisa ali localizadas ${ }^{10}$.

No que se refere especificamente às estratégicas atividades de Pesquisa, Desenvolvimento e Inovação (P\&D\&I) aplicadas à bioprospecção, isto é, ao processo de identificação de princípios ativos (com potencial farmacológico ou terapêutico) obtidos a partir de extratos vegetais ou de toxinas animais, e tendo como foco o aproveitamento sustentável da biodiversidade amazônica, o panorama internacional e especialmente o nacional e regional é, sob todos os aspectos, menos favorável que aquele de aproximadamente há uma década e meia. Diversos programas nessa área foram criados na época em países com rica biodiversidade - sobretudo aqueles com florestas tropicais como o Brasil - contando então com o impulso favorável propiciado pela recém-instituída Convenção da Diversidade Biológica (CDB) e com um ambiente propício para o estabelecimento de parcerias entre agências governamentais, instituições e grupos de pesquisa e o setor empresarial desse segmento.

No caso brasileiro, e em particular no da Amazônia, aqueles programas concentraram inicialmente o seu foco no desenvolvimento de fitomedicamentos, tomando como ponto de partida a literatura científica disponível (o inventário biológico, a química de produtos naturais e as pesquisas farmacológicas) e o vasto conhecimento das populações tradicionais sobre as chamadas plantas medicinais, algumas delas de amplo domínio popular. Os resultados desses esforços, entretanto, mostraram-se até hoje praticamente nulos, especialmente no que se refere ao desenvolvimento de novos fármacos de base natural ou daqueles derivados e sintetizados a partir de biomoléculas e compostos de origem vegetal ou animal e que demonstrem viabilidade econômica, isto é, que sejam testados, aprovados, certificados, patenteados, licenciados e produzidos em escala industrial.

Um conhecido grupo de fatores é, em grande parte, responsável por esse fracasso, destacando-se pelo menos três deles como cruciais. Primeiro, porque rapidamente descobriu-se que não basta possuir uma rica biodiversidade se a ela não se associar um enorme esforço concentrado

\footnotetext{
9 Uma das prioridades do Plano Amazônia Sustentável (PAS), em sua versão atual (Secretaria de Assuntos Estratégicos, 2008).

10 Os aspectos principais desse quadro de carências e a importância estratégica dos investimentos em C\&T e P\&D para o desenvolvimento da Amazônia em bases avançadas e sustentáveis estão muito bem sintetizados no documento recentemente elaborado pela Academia Brasileira de Ciências - Proposta da Academia Brasileira de Ciências para um Novo Modelo de Desenvolvimento para a Amazônia (versão 11.05.2008), intitulado "Amazônia: Desafio Brasileiro do Século XXI - A necessidade de uma Revolução Científica e Tecnológica", no qual o montante de investimentos para os próximos dez anos nessa área foi estimado em $\mathrm{R} \$ 30$ bilhões, devendo ser concentrados principalmente na criação de três institutos especializados, em programas de pós-graduação e na modernização das instituições da região.
}

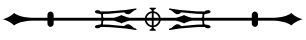


de pesquisas de ponta, isto é, que sejam capazes de cobrir todos os imprescindíveis steps da bioprospecção, que vão desde o inventário biológico e a coleta seletiva até o patenteamento e o licenciamento do produto, passando pelas etapas especificamente laboratoriais e os ensaios clínicos. Afinal, os especialistas e empresários da área sabem que não existem fármacos naturais stricto sensu, mas produtos que requerem, em geral, um longo e complexo processo de pesquisas e desenvolvimento (entre cinco e oito anos, em média) e, portanto, altos investimentos (em alguns casos, para além de duas centenas de milhões de dólares), sempre contando com uma altíssima taxa de riscos (menos de 1\% dos protótipos tornam-se, de fato, fármacos com viabilidade comercial).

Segundo, é imprescindível que essa pesquisa seja desenvolvida com metas de longo prazo e por meio da atuação de grupos de diversos especialistas fortemente engajados e concentrados na obtenção de resultados definidos, que possam contar com o apoio de redes de pesquisa de diversos portes e escalas. Ademais, a experiência internacional tem demonstrado que esse é um dos segmentos mais competitivos não apenas da bioindústria, mas da indústria contemporânea em geral, ostentando atualmente uma fortíssima tendência à concentração de capitais e, portanto, amplamente dominado pelas grandes empresas transnacionais que têm sede em não mais que quatro países. Por isso, são elas, justamente, as únicas hoje em dia que reúnem todas as condições para estabelecer não apenas os horizontes de mercado, mas também a logística requerida por esse tipo de empreendimento, mobilizando vultosos recursos e os aplicando em P\&D (em média, acima de $10 \%$ do seu faturamento líquido anual) nas cada vez mais custosas etapas que abrangem, além das pesquisas laboratoriais, os ensaios clínicos, o patenteamento nos mercados internacionais (e a posterior defesa jurídica dessas patentes em cada país), o licenciamento e o marketing.

Terceiro, está amplamente comprovado pelos meios científicos e empresariais que, sobretudo nesta fase globalizada marcada pela alta competição, o alvo preferencial da área de P\&D dessas grandes empresas está mudando com rapidez. Hoje, ele tende fortemente para o desenvolvimento de drogas sintéticas ${ }^{11}$ voltadas para um relativamente pequeno grupo de alvos terapêticos de importância crucial para as populações de um grupo não superior a cinco dezenas de países, em detrimento daquelas naturais semiprocessadas, as baseadas em compostos naturais ou mesmo aquelas que são deles derivadas. Além disso, essa tendência atual de exclusão dos produtos da bioprospecção do portfólio de investimentos das grandes empresas desse segmento tem sido atribuída por elas como uma reação do setor aos entraves representados pelas graves indefinições de natureza normativa e regulatória nos países chamados de 'megabiodiversos' e, em alguns casos, como no Brasil, com o agravante de que podem desencadear turbulências e prejuízos à sua imagem, decorrentes de experiências e projetos pioneiros e mal sucedidos desse tipo. Tudo indica, portanto, que as grandes empresas tenderão a afastarse cada vez mais dos até recentemente tão decantados caminhos promissores da bioprospecção ${ }^{12}$.

Em síntese, é preciso reconhecer que se os avanços no processo de aproveitamento sustentável da biodiversidade

11 Diversos estudos, especialmente aqueles elaborados pelos farmacologistas, indicam essa tendência atual, como o de Ferreira (2002).

12 Esse foi o caso da polêmica que envolveu a tentativa de estabelecer um acordo de cooperação entre a Organização Social Bioamazônia e a Novartis, que visava implementar um projeto de bioprospecção, tendo como alvo o desenvolvimento de fármacos com base na identificação de princípios ativos em micro-organismos da biodiversidade amazônica. Exemplo similar é aquele relativo ao insucesso da parceria da Extrata (empresa nacional de bioprospecção) com a Glaxo Wellcome, em torno de projetos de P\&D nessa área, que tinham como principal suporte um 'Banco de Extratos' formado a partir de espécies vegetais amazônicas. Além disso, em recente entrevista (julho de 2008) no jornal "O Estado de São Paulo", o Assessor Sênior de Políticas do Smithsonian Institute e Consultor da CDB, Leonard Hirsch, enfatizou que os graves problemas envolvendo a regulamentação dessa matéria, além dos entraves burocráticos de todo tipo, são fatores que devem ser considerados como os principais responsáveis pelo evidente desinteresse atual das empresas por projetos de P\&D de novos fármacos baseados na bioprospecção.

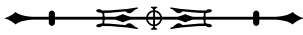


amazônica e da bioindústria na área da produção de fitofármacos ou fármacos derivados dependerem, como nos demais casos, de uma forte participação dos investimentos e da atuação direta das empresas-líderes do segmento, então o cenário, nesse caso, não é dos melhores.

De modo geral, os problemas mais relevantes, que tendem a frear na atual conjuntura o pleno desenvolvimento dos sistemas emergentes na região, podem ser assim resumidos:

a) As comprovadas impropriedades da legislação e das diversas normas específicas federais destinadas à regulação do acesso ao patrimônio genético para fins de pesquisa e, especialmente, para projetos de bioprospecção. Esse quadro é agravado pelo atual formato burocrático, aliado à obsolescência e ao esvaziamento do Conselho de Gestão do Patrimônio Genético do Ministério do Meio Ambiente (MMA), que constitui não apenas um entrave para o avanço das pesquisas básicas sobre a biodiversidade do país, mas também um fator que tem repelido e anulado, na prática, qualquer possibilidade de investimento das empresaslíderes nacionais e internacionais em projetos de P\&D nesse setor. Basta acessar o site do MMA e observar o desempenho atual desse Conselho para comprovar a gravidade do atual quadro de crise;

b) A imensa quantidade e a notória sobreposição de leis, decretos, portarias e resoluções dos órgãos de governo federais e estaduais e de agências específicas, como a Agência Nacional de Vigilância Sanitária (ANVISA), por exemplo, que malgrado pretenderem estabelecer mecanismos de normatização, de regulação e de modernização para esses antigos e novos segmentos relacionados aos bioprodutos em geral, tem constituído no mais das vezes no principal entrave ao seu pleno desenvolvimento. Sob esse aspecto, é notória a inadequação das exigências legais e técnicas dos planos de manejo face às condições materiais predominantes nos pequenos empreendimentos florestais da região. Este é o caso de algumas normas técnicas específicas da ANVISA que são exigidas atualmente para a aprovação e o licenciamento de produtos no segmento dos cosméticos em geral e que demandam longos, penosos e custosos procedimentos, tais como a realização de testes químicos e toxicológicos, entre outros. $\bigcirc$ mais emblemático desse tipo de entrave é o representado pelo conjunto de normas da ANVISA atualmente aplicadas aos processos de aprovação e licenciamento para os fitomedicamentos, sendo que algumas delas incluem até mesmo a exigência da realização de testes clínicos para a comprovação da eficácia terapêutica desses produtos. Especialistas da área têm apontado que normas desse tipo podem constituir, na prática, uma quase intransponível barreira para os pequenos empreendimentos industriais do país e, especialmente, nos casos daqueles situados na Amazônia. Como consequência, elas podem contribuir para acentuar o processo de concentração econômica no estratégico mercado dos bioprodutos;

c) Finalmente, e como assinalado acima, uma considerável parcela de responsabilidade no conjunto desses entraves que ainda freia o pleno desenvolvimento da bioindústria na Amazônia, em particular, deve ser atribuída ao insucesso dos programas federais até aqui direcionados para a área da bioprospecção. Sob esse aspecto, devem ser tomados como experiências emblemáticas o atual esvaziamento do PROBEM e a crônica paralisia do Centro de Biotecnologia da Amazônia (CBA), em Manaus. Neste caso, um quadro que decorre, sobretudo, da sua crônica indefinição institucional, organizacional e operacional, além do seu isolamento em relação às redes de pesquisa nacionais e internacionais da área e à atuação das empresas-líderes do segmento. 


\section{TENDÊNCIAS, DESAFIOS E PERSPECTIVAS DO MANEJO FLORESTAL}

Entre os aqui denominados sistemas produtivos convencionais, a indústria madeireira na Amazônia ainda constitui uma das principais atividades econômicas da região, empregando atualmente em torno de 400.000 pessoas diretamente, e mais de um milhão sob modalidades diversas de participação. Ao longo das três últimas décadas, principalmente, essa evolução pode ser avaliada mediante o uso de indicadores diversos, tais como o aumento do número de empreendimentos legalizados e clandestinos (aproximadamente 3.000), o volume total da produção de madeira em tora (14,6 milhões de $m^{3}$ ) ou processada, o alargamento e a diversificação das sub-regiões e áreas abrangidas por essa indústria (Yared, 2008).

O seu dinamismo atual está basicamente associado ao crescimento do mercado (nacional e internacional) nos segmentos de madeira bruta e processada oriunda de florestas nativas, à mobilidade das fronteiras de ocupação, ao adensamento e à modernização das redes de circulação (rodoviária e hidroviária) e, de modo geral, à sua associação com a expansão da pecuária e das atividades agroindustriais recentes, com destaque para o cultivo da soja.

Inúmeros estudos recentes demonstram que, apesar das exigências da legislação ambiental em vigor, como a aprovação de planos de manejo e as autorizações para o transporte, essa atividade ainda se desenvolve predominantemente à margem dos sistemas oficiais de controle, operando, sobretudo, com base em sistemas arcaicos de exploração e com baixos níveis de produtividade (grande desperdício de biomassa), constituindo atualmente um dos principais vetores de impactos ambientais sobre os ecossistemas amazônicos. Raros são os empreendimentos na região que operam de acordo com as normas legais em vigor e com os procedimentos previstos pelos sistemas de manejo florestal sustentável ou controlado, adotados internacionalmente nos processos de certificação para o segmento, atualmente agrupados no Forest Stewardship Council (FSC).

No mercado brasileiro como um todo, entretanto, há indicações de que a demanda dos mercados de consumo por madeira certificada apresenta tendência de crescimento, ainda que restrita aos produtos semiprocessados ou processados destinados aos mercados internacionais ${ }^{13}$.

A indústria de transformação nesse setor, concentrada basicamente no sul e no sudeste, e especialmente aquela dedicada à produção moveleira e de artefatos mais elaborados, tem apresentado atualmente uma forte tendência para a utilização de matérias-primas madeireiras certificadas, mas apenas para aquelas extraídas de florestas plantadas e com espécies em franco processo de expansão nessas regiões, como são os casos do Pinus e do Eucalyptus.

Esse crescimento do processo de certificação, entretanto, ainda não alcançou a produção madeireira de florestas nativas, como as da Amazônia. No ano de 2008, a produção certificada na região contou com 26 empreendimentos empresariais e comunitários, sendo dois deles mistos (madeireiros e não madeireiros). Esse número ainda é evidentemente insignificante (menos de 1\%) quando considerados o universo dos empreendimentos atualmente em operação (formais e informais), o volume total da produção, as áreas florestais abrangidas e as escalas de distribuição regional (Figura 3).

Sob esse aspecto, é flagrante o isolamento da região amazônica em relação ao atual e acelerado processo de modernização do país, e não apenas no que se refere ao setor madeireiro mais avançado de outras regiões (baseado em florestas plantadas), como também à estrutura industrial em geral, já que o país ocupa hoje a $5^{a}$ posição mundial em número de empresas certificadas segundo as normas internacionais agrupadas no FSC.

Deve ser registrado, por outro lado, que além da forte demanda do mercado internacional por madeira

\footnotetext{
13 Segundo o FSC, havia em 2005 no mundo 689 empreendimentos madeireiros certificados em 61 países. No ano de 2008, esse número passou para 983 empreendimentos em 79 países.
}

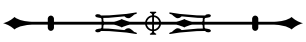




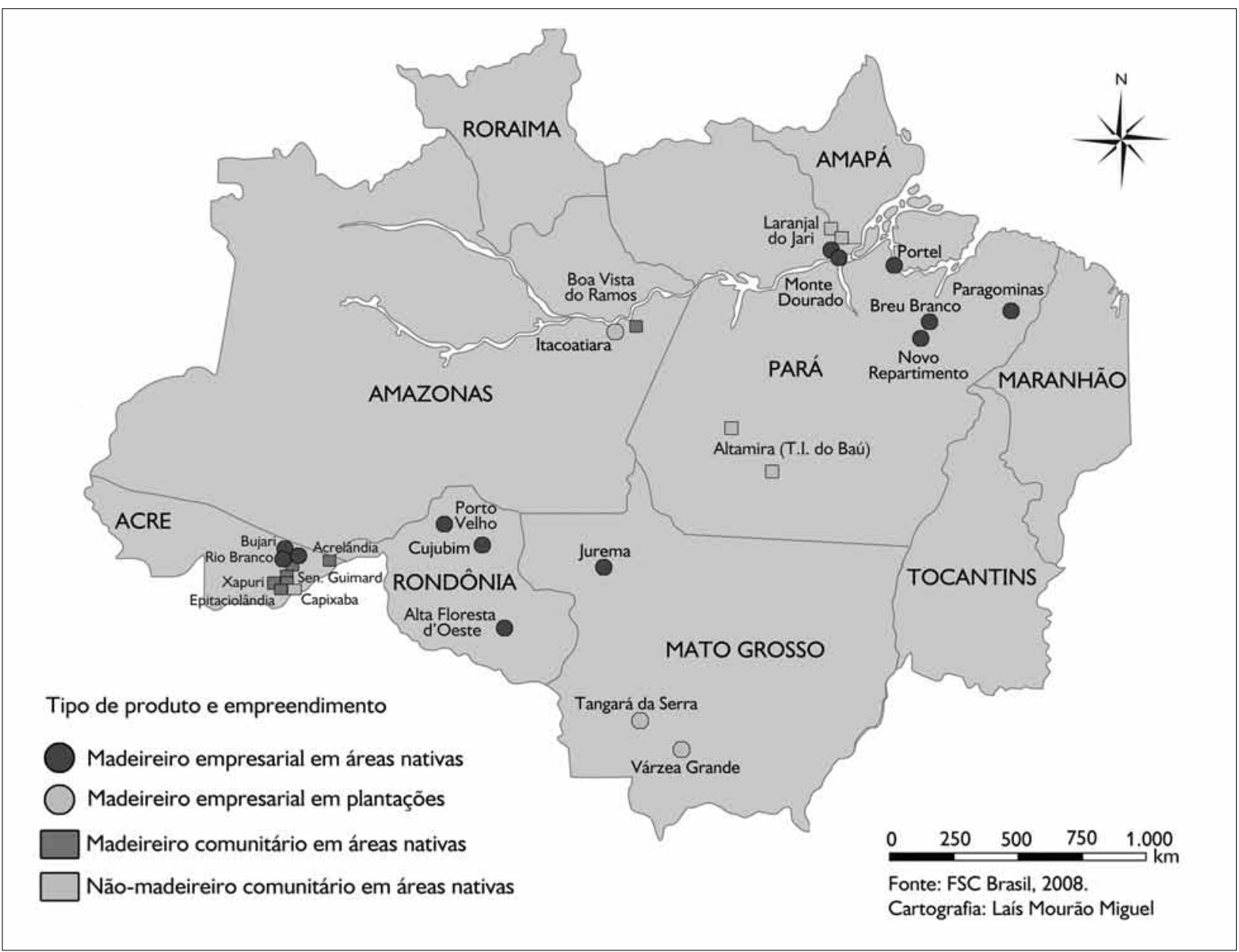

Figura 3. Áreas florestais certificadas nos estados da Amazônia Legal (2008).

certificada e do atual esforço governamental para aperfeiçoar os sistemas de controle sobre esse setor, outro vetor que tem contribuído para introduzir mudanças no segmento está associado ao crescimento da indústria moveleira na região. Um estudo específico sobre a atividade no Pará ${ }^{14}$ concluiu que essa indústria tem desempenhado um papel importante para a modernização do setor madeireiro em geral, na medida em que ela é "intensiva em emprego e ajuda a reduzir os impactos ambientais das serrarias, uma vez que utiliza as aparas e resíduos de madeira dessas empresas como matériaprima" (Carvalho et al., 2007, p. 17).

A modernização desse segmento também se expressa na iniciativa em curso de implantar um Pólo Moveleiro no Distrito Industrial de Manaus, um projeto que tem gerado expectativas divergentes sobre os seus potenciais impactos na indústria madeireira como um todo. Em recente documento técnico da Federação das Indústrias do Estado do Amazonas (FIEAM) sobre

14 Os autores analisaram o desempenho econômico de 84 empresas (em um universo de 384). Entre as diversas variáveis consideradas, incluíram algumas não diretamente econômicas, como o controle de qualidade e o uso de normas técnicas no processo produtivo, e concluíram que por volta de $70 \%$ encontram-se no que consideraram como um "estágio intermediário" quanto aos parâmetros gerais de competitividade.

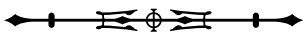


o desempenho do Pólo Industrial de Manaus (PIM) em 2007, está destacado que a intensificação do controle e da fiscalização do Instituto Brasileiro do Meio Ambiente e dos Recursos Naturais Renováveis (IBAMA) e do órgão ambiental estadual (Instituto de Proteção Ambiental do Amazonas - IPAAM) nos últimos anos tem provocado uma rápida desaceleração desse segmento industrial, na medida em que os empreendedores não teriam condições de atender ao conjunto de exigências legais e técnicas previstas nos Planos de Manejo Florestal.

Por outro lado, representantes dos pequenos empresários desse setor alegam que o futuro pólo madeireiro inevitavelmente promoveria um processo de concentração no mercado, já que apenas as grandes empresas teriam condições de realizar os investimentos para plantas industriais de grande escala e, ao mesmo tempo, de operar em consonância com as normas legais e técnicas que regulam atualmente essa atividade.

Uma pesquisa recente sobre o perfil atual da indústria moveleira em Manaus (Floresta Viva Amazonas, 2006) baseou-se em um detalhado levantamento sobre esse setor a partir de um universo com 110 pequenos empreendimentos (marcenarias), voltados para a produção semi-artesanal de móveis e instalações residenciais, 30 pequenas indústrias com lojas próprias, 30 fornecedores de lojas e 30 lojas de móveis. Tratam-se, em sua grande maioria, de processadores e fabricantes que se utilizam de madeiras de lei (principalmente o cedro e o angelim) extraídas em diversos municípios do interior (com destaque para Manacupurú, Lábrea, Itacoatiara e Parintins). Os autores chamam a atenção para duas características relevantes das relações entre a exploração florestal do interior e os processadores industriais da capital: a predominância de madeiras de lei em toras ou em pranchas adquiridas de produtores florestais baseados em sistemas clandestinos ou ilegais de extração, comercialização e transporte. Ao mesmo tempo, constataram o rápido crescimento do volume de matérias-primas oriundas de Roraima, que chegam a Manaus por rodovia asfaltada. Por outro lado, identificaram também uma crescente demanda por embalagens industriais pelas empresas do PIM (os pallets) e chamam a atenção para o fato de que essas empresas estabelecem exigências rígidas para que tais produtos sejam processados a partir de madeira certificada, um fator que tem impulsionado o processo de legalização e de modernização do segmento.

Outra tendência atual que deve ser destacada tem sido representada pelas novas experiências envolvendo os empreendimentos madeireiros comunitários, a exemplo do que tem ocorrido em maior escala com os produtos florestais não-madeireiros. Nos últimos anos, essa nova modalidade de exploração madeireira tem constituído uma alternativa viável para combinar a conservação da floresta e oferecer oportunidades econômicas para as comunidades locais. Além disso, a busca pela certificação florestal tem estimulado comunidades, organizações governamentais e não governamentais e agências de cooperação para a implementação e a disseminação de um novo padrão tecnológico para esses sistemas na região.

Até 2006, havia 176 Planos de Manejo Florestal Comunitário em execução. Onze desses empreendimentos já haviam obtido certificação segundo as exigências do FSC. Também nesses casos, os empreendimentos têm envolvido a constituição de cooperativas de pequenos produtores e um crescente relacionamento com os mercados. Há outras inovações desse gênero, como são os casos das parcerias entre empresas madeireiras e comunidades ou cooperativas de pequenos produtores, geralmente envolvendo os assentamentos rurais e operando segundo planos de manejo controlado 15 .

Entre as inovações atuais especificamente no campo das políticas públicas voltadas para a modernização e a introdução de padrões de sustentabilidade para esse

\footnotetext{
15 Sobre essas experiências, ver Lima et al. (2003). Segundo esse estudo, uma das experiências mais conhecidas ocorre em um assentamento rural do município de Santarém, Pará, envolvendo um empresário florestal e seis comunidades, com mais de 360 famílias de pequenos produtores, na qual a empresa promove a regularização fundiária das pequenas propriedades e a alocação de infraestrutura, em troca de parte da madeira extraída no local.
}

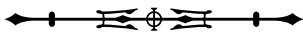


setor, destaca-se a experiência do governo do estado do Amazonas, que tem sido desenvolvida no âmbito do seu Programa Zona Franca Verde, lançado em 2003 pela Secretaria de Desenvolvimento Sustentável (SDS) e pelo IPAAM, e executado pela Agência de Florestas e Negócios Sustentáveis (AFLORAM). Esse programa visa dar apoio técnico, legal e financeiro para "a implantação de Plano de Manejo Florestal Sustentável com Procedimentos Simplificados (PMFSPS), junto aos pequenos produtores de madeira do interior do Estado" (Pirani, 2007, p. 11). Iniciado pelos municípios das regiões do Alto Solimões e do Juruá, ele estendeu-se em 2006 para todo o estado.

Um aspecto essencial desse programa é representado pela iniciativa que visou simplificar os procedimentos para a aprovação e o controle dos planos de manejo florestal para pequenos empreendimentos, medida que foi concretizada mediante convênio entre a SDS e o IBAMA, pelo qual o órgão estadual adquiriu autonomia de gestão nessa área, especialmente no que se refere aos Planos de Manejo Florestal Sustentável em Pequena Escala (PMFSPS), aplicados para explorações em estabelecimentos não superiores a 500 ha $^{16}$.

Além disso, inovações de natureza especificamente técnica foram introduzidas pelo programa, tais como a simplificação dos procedimentos previstos no manejo stricto sensu, pela qual se procurou implantar alternativa mais adequada para empreendimentos comunitários. Desse modo, foi adotado o sistema desenvolvido a partir de uma experiência bem sucedida no Acre, no âmbito do projeto de Assentamento Agroextrativista do Seringal da Cachoeira, no município de Xapuri ${ }^{17}$.

Na fase piloto do programa amazonense (2003), foram elaborados 692 projetos de manejo florestal abrangendo pequenos empreendimentos de 15 pólos madeireiros em 59 municípios, tendo sido licenciados 263, ou 38\% do total.

A avaliação dessa experiência demonstrou que, apesar do vulto do programa em termos de inovação no arranjo institucional e na área de abrangência, bem como nos recursos humanos, técnicos e financeiros envolvidos, os resultados alcançados mostraram-se desproporcionais ao esforço. As principais causas do insucesso foram assim identificadas:

a) Dificuldades nos processos de licenciamento, apesar da simplificação introduzida pelo programa. Entre o protocolo da solicitação e a sua aprovação final é necessário que o projeto percorra dez diferentes etapas, incluindo uma vistoria in loco. Após o corte da madeira, o produtor deve obter a Autorização de Transporte para Produtos Florestais (ATPF) (substituída em 2006 pelo Documento de Origem Florestal - DOF) junto ao IPAAM, um documento cuja expedição está condicionada à inexistência de pendência de qualquer natureza junto ao IBAMA;

b) Complexidade técnica e legal envolvida com as exigências de realização de inventário florestal. A elaboração do plano de manejo em todas as etapas deve ser realizada por profissional qualificado e credenciado junto ao órgão ambiental. No caso desse programa, a AFLORAM presta esse serviço junto aos pequenos empreendedores, mas o número reduzido de técnicos e as grandes distâncias entre os municípios são fatores que contribuem para a morosidade do processo. Além disso, a legislação federal exige que o empreendedor apresente ao órgão ambiental o comprovante de regularização fundiária, o que em certos casos é praticamente impossível, como aqueles de projetos localizados em terras públicas, áreas de conservação ou mesmo em terras indígenas;

${ }^{16}$ Com a publicação da Lei Federal n. 11.284, de 2 de março de 2006, que regulamenta a exploração de florestas públicas, esse princípio de autonomia de gestão dos estados torna-se efetivo, já que a eles fica atribuída competência para aprovar e controlar os planos de manejo nas áreas sob a sua jurisdição.

17 Trata-se do sistema baseado no conceito de "árvores mães, filhas e netas", pelo qual as primeiras só são abatidas quando tiverem produzido muitas filhas e netas (Pirani, 2007, p. 25).

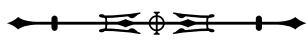


c)

Entraves legais à comercialização, representados pela exigência de que a venda do produto só pode ser feita para pessoas jurídicas legalizadas, um dispositivo que estimula na prática a informalidade, já que são raros os casos de serrarias e processadores em dia com os requisitos legais nos mercados locais de madeira e de movelaria do estado.

Em síntese, permanece o imenso desafio de aperfeiçoar, disseminar e controlar o manejo florestal sustentável no âmbito da produção madeireira nas florestas nativas da região, a qual se desenvolve atualmente com o predomínio dos empreendimentos privados de todos os portes e estruturas (formais e informais). Diversos levantamentos e estudos de especialistas da área demonstram que há obstáculos de todo tipo a superar para tornar técnica e economicamente viável essa exploração sob forma sustentável e, portanto, legalizada, sendo relevantes os seguintes: os custos de produção e o preço final do produto sempre serão mais elevados quando forem adotados integralmente os sistemas de manejo, vis-à-vis os sistemas tradicionais. Este tem sido considerado um poderoso fator estrutural de inibição para as mudanças pretendidas, o que indica a necessidade de focar as políticas e as ações não apenas nas esferas técnicas da exploração, como também no comportamento dos mercados de consumo desses produtos. Em outros termos, é essencial que os consumidores de produtos finais de madeira de lei concordem em arcar com os custos adicionais relacionados às exigências técnicas e legais dos mecanismos de certificação de qualidade ambiental (Sabogal et al., 2006).

Outros problemas estruturais são a carência de recursos humanos qualificados, o conservadorismo das empresas do setor, a persistência de um complexo e por vezes inadequado emaranhado de leis e normas infralegais, e a pesada burocracia envolvida na gestão e no controle dessas atividades (que induziria o empreendedor para práticas ilegais), ao lado da sempre reconhecida fragilidade dos sistemas de fiscalização. $\bigcirc$ abrangente conjunto de normas legais, tais como leis, decretos, portarias e resoluções que regulam as atividades relacionadas à exploração florestal em geral - e madeireira em particular no país, especialmente na Amazônia - bem ilustra essa situação atual.

Em suma, este texto procurou examinar as tendências dominantes na exploração dos sistemas estruturados nas últimas décadas para a exploração de produtos florestais não madeireiros, madeireiros e cultivos nativos e exóticos. Os processos em curso na região refletem, no geral, o desenvolvimento de novas formas de organização comunitária, bem como o papel das empresas-líderes na modernização da produção e no acesso dos produtores aos mercados. Finalmente, o trabalho identificou a crescente importância das contribuições da pesquisa em Ciência e Tecnologia como força propulsora de inovações tecnológicas e da expansão dessas atividades.

\section{REFERÊNCIAS}

ALLEGRETTI, M. H. A Gestão Comunitária da Floresta e o Desenvolvimento da Amazônia. Braślia: CGEE, 2008.

BECKER, B. K. Reflexões sobre a geopolítica e a logística da soja na Amazônia. In: BECKER, B. K.; ALVES, D. E.; COSTA, W. M. (Orgs.). Dimensões humanas da Biosfera-Atmosfera na Amazônia. São Paulo: EDUSP, 2007a. p. 113-128.

BECKER, B. K. Logística e nova configuração do território brasileiro: que geopolítica será possível? In: DINIZ, C. C. (Org.). Políticas de desenvolvimento regional: desafios e perspectivas à luz das experiências da União Européia e do Brasil. Brasília: Ed. UnB, 2007b. p. 267-300.

BECKER, B. K. Amazônia: geopolítica na virada do III Milênio. Rio de Janeiro: Garamond, 2004.

CARVALHO, D. F.; SANTANA, A. C.; NOGUEIRA, A. K. M.; MENDES, F. A. T.; CARVALHO, A. C. Análise do desempenho competitivo da indústria de madeira do estado do Pará. Amazônia: Ciência \& Desenvolvimento, Belém, v. 2, n. 4, p. 17-36, jan.jun. 2007.

CLAY, Jason W.; SAMPAIO, Paulo T. B.; CLEMENT, Charles R. Biodiversidade amazônica - exemplos e estratégias de utilização. Manaus: INPA/SEBRAE, 1999.

COSTA, W. M. Tendências recentes na Amazônia: os Sistemas Produtivos Emergentes. In: BECKER, B.; ALVES, D.; COSTA, W. M. (Orgs.). Dimensões humanas da biosfera-atmosfera na Amazônia. São Paulo: EDUSP, 2007. p. 81-112. 
FERREIRA, S. H. Medicamentos a partir de plantas medicinais no Brasil. Rio de Janeiro: Academia Brasileira de Ciências, 2002.

FLORESTA VIVAAMAZONAS. O Setor Madeireiro/Moveleiro de Manaus (caracterização dos atores e das cadeias). Documento de Trabalho 2, Manaus, 2006.

LIMA, Erivelthon; LEITE, Antonio; NEPSTAD, Daniel; KALIF, Kemel; AZEVEDO-RAMOS, Claudia; PEREIRA, Cássio; ALENCAR, Ane; SILVA JR., Urbano Lopes; MERRY, Frank. Florestas familiares: um pacto sócio-ambiental entre a indústria madeireira e a agricultura familiar da Amazônia. Belém: IPAM, 2003.

MAIA, J. G. S.; ZOGHBI, M. G. B.; ANDRADE, E. H. A. Plantas aromáticas na Amazônia e seus óleos essenciais. Belém: MPEG, 2001.

MIGUEL, L. M. Uso sustentável da biodiversidade na Amazônia brasileira: experiências atuais e perspectivas das bioindústrias de cosméticos e fitoterápicos. 2007. Dissertação (Mestrado em Geografia) - Universidade de São Paulo, São Paulo, 2007.

MONTEIRO, K. F. G.; SILVA, A. R. F;; SOUZA, C. T.; CONCEIÇÃO, E. R.; PALHETA, R. P. O Cultivo do dendê como Alternativa de produção para a Agricultura Familiar e sua inserção na cadeia do Biodiesel no Estado do Pará. In: CONGRESSO DA REDE BRASILEIRA DE TECNOLOGIA DE BIODIESEL, 1., 2006, Brasília. Congresso da Rede Brasileira de Tecnologia de Biodiesel: artigos técnico-científicos. Brasília: Ministério da Ciência e Tecnologia, 2006. Disponível em: <http://www.biodiesel.gov.br/docs/congressso2006/agricultura/ CultivoDende.pdf>. Acesso em: 22 fev. 2009.
PIRANI, A. M. Análise do componente Manejo Florestal Madeireiro do Programa Zona Franca Verde no Estado do Amazonas: da intenção à ação. 2007. Dissertação (Mestrado em Biologia Tropical e Recursos Naturais) - Universidade Federal do Amazonas/Instituto Nacional de Pesquisas da Amazônia, Manaus, 2007.

REVILLA, J. Plantas da Amazônia - oportunidades econômicas e sustentáveis. Manaus: INPA/SEBRAE, 2000.

RSPO. Roundtable on Sustainable Palm Oil. Certification Systems Final Document Approved by RSPO Executive Board, june, 2007. Disponível em: <http://www.rspo.org/files/resource centre/ RSPO\%20certification\%20systems.pdf>. Acesso em: 22 fev. 2009.

SABOGAL, César; POKORNY, Benno; BERNARDO, Pedro; MASSIH, Farid; BOSCOLO, Marco; LENTINI, Marco; SOBRAL, Leonardo; VERÍSSIMO, Adalberto; SILVA, Natalino; ZWEEDE, Johan. Manejo Florestal Empresarial na Amazônia Brasileira. (Relatório Síntese). Belém: CIFOR/IMAZON/EMBRAPA/Fundação Floresta Tropical, 2006.

SECRETARIA DE ASSUNTOS ESTRATÉGICOS. Plano Amazônia Sustentável (ações prioritárias). Brasília: Presidência da República/ SAE, 2008.

YARED, J. A. G. A produção madeireira na Amazônia: oportunidades para o desenvolvimento econômico sócio-ambiental. Brasília: CGEE, 2008.

Recebido: 14/05/2009

Aprovado: 11/03/2010

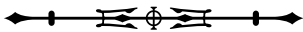

